\title{
A structural and functional comparison of nematode and crustacean PDH-like sequences
}

\author{
E. Meelkop ${ }^{\mathrm{a}, 1,2}$, H.G. Marco ${ }^{\mathrm{b}, 2,3}$, T. Janssen ${ }^{\mathrm{a}, 1}$, L. Temmerman ${ }^{\mathrm{a}, 1}$, M.P.M. Vanhove ${ }^{\mathrm{c}, 4}$, L. Schoofs ${ }^{\mathrm{a}, *}$ \\ a Laboratory of Functional Genomics and Proteomics, K.U. Leuven, Naamsestraat 59, 3000 Leuven, Belgium \\ ${ }^{\mathrm{b}}$ Zoology Department, University of Cape Town, Rondebosch ZA-7701, South Africa \\ c Laboratory of Animal Diversity and Systematics, K.U. Leuven, Charles Deberiotstraat 32, 3000 Leuven, Belgium
}

\section{A R T I C L E I N F O}

\section{Article history:}

Received 16 September 2011

Received in revised form 5 November 2011

Accepted 7 November 2011

Available online $\mathrm{xxx}$

\section{Keywords:}

Caenorhabditis elegans

Pigment dispersing hormone

Pigment dispersing factor

Pigment dispersion

PDF receptors

\begin{abstract}
A B S T R A C T
The elucidation of the whole genome of the nematode Caenorhabditis elegans allowed for the identification of ortholog genes belonging to the pigment dispersing hormone/factor (PDH/PDF) peptide family. Members of this peptide family are known from crustaceans, insects and nematodes and seem to exist exclusively in ecdysozoans where they play a role in different processes, ranging from the dispersion of integumental and eye (retinal) pigments in decapod crustaceans to circadian rhythms in insects and locomotion in C. elegans. Two pdf genes (pdf-1 and pdf-2) encoding three different peptides: PDF-1a, PDF-1b and PDF-2 have been identified in C. elegans. These three C. elegans PDH-like peptides are similar but not identical in primary structure to PDHs from decapod crustaceans. We investigate whether this divergence has an influence on the pigment dispersing function of the peptides in a decapod crustacean, namely the shrimp Palaemon pacificus. We show that $C$. elegans PDF-1a and b peptides display cross-functional activity by dispersing pigments in the epithelium of $P$. pacificus at physiological doses. Moreover, by means of a comparative amino acid sequence analysis of nematode and crustacean PDHlike peptides, we can pinpoint several potentially important residues for eliciting pigment dispersing activity in decapod crustaceans. Although there is no sequence information on a receptor for PDH in decapod crustaceans, we postulate that there is general conservation of the PDH/PDF signaling system based on structural similarities of precursor proteins and receptors (including those from a branchiopod crustacean and from C. elegans).
\end{abstract}

(c) 2011 Elsevier Inc. All rights reserved.

\section{Introduction}

Early experiments with the shrimp Crangon crangon showed the existence of pigment dispersing substances in the eyestalks of decapod crustaceans [19]; this peptidic substance is known as pigment-dispersing hormone ( $\mathrm{PDH})$. The first $\mathrm{PDH}$ to have its amino acid sequence fully determined was purified from Pandalus borealis [7]. Today, over 45 different purified PDH-like peptide sequences (based on structural similarity) are known to exist in two major phyla of the Ecdysozoa: Arthropoda (insects and crustaceans) and Nematoda [reviewed in 23], although transcripts have also been

\footnotetext{
* Corresponding author. Tel.: +32 16 323917; fax: +32 16323902.

E-mail addresses: ellen.meelkop@bio.kuleuven.be (E. Meelkop), heather.marco@uct.ac.za (H.G. Marco), tom.janssen@bio.kuleuven.be (T. Janssen), liesbet.temmerman@bio.kuleuven.be (L. Temmerman), maarten.vanhove@bio.kuleuven.be (M.P.M. Vanhove), liliane.schoofs@bio.kuleuven.be (L. Schoofs).

1 Tel.: +32 16 323917; fax: +32 16323902 .

2 These authors contributed equally to this work.

3 Tel.: +27 21 6503606; fax: +27216503301.

4 Tel.: +3216323918.
}

identified in Onychophora and Tardigrada [2]. In arthropods, these peptides are octadecapeptides, while sequence lengths of 20 and 22 amino acid residues occur in nematodes [15]. PDHs are further categorized as $\alpha$ - and $\beta-\mathrm{PDH}$, based on the resemblance to the PDH isolated from $P$. borealis and from the crab Uca pugilator, respectively, as well as considering peptide acidity and/or charge [7,36].

Generally, the term PDH is reserved for crustaceans where a clear hormonal function was demonstrated in epidermal chromatophores, as well as retinal pigment cells, while PDH-like peptides in insects and nematodes are referred to as pigment dispersing factor (PDF) [reviewed in 23]. As such, the first PDF to be sequenced from an insect, namely the grasshopper Romalea microptera, was identified by its pigment dispersing activity in the crab $U$. pugilator [33]. Neither insects nor nematodes display the integumental color changes observed in decapod crustaceans and the role of PDFs in insects appears to be linked to circadian locomotor rhythm [29] and general coordination of the endogenous circadian clock [37]. Interestingly, PDH may also be involved with circadian entrainment (adaptation to daily rhythms in the environment) in crustaceans, as shown in the case of the crayfish Procambarus clarkii and Cherax destructor [39]. 
Sequencing of the entire nematode genome has made it possible for researchers to search for various gene homologs encoding specific ligands and their receptors. Recently, we identified the genes encoding the PDF signaling system in Caenorhabditis elegans: three different PDF receptor isoforms: PDFR-1a, b and c are encoded by the C. elegans pdfr-1 gene [14], and three PDF peptides: PDF-1a, PDF-1b and PDF-2 [15] have been identified. Thus far, nematode PDF receptor(s) and PDF peptides were shown to be involved in the control of locomotion [14,15, own unpublished data]. Furthermore, all three PDF peptides are able to activate each of the three receptor isoforms, albeit with different potencies [14].

The C. elegans PDF peptides differ in length, as well as in amino acid composition when compared with the 18 amino acid-long PDH-like peptides of arthropods. Also, given the phylogenetic distance between nematodes and arthropods, we were interested to see whether the peptide and receptor sequence differences would influence the biological activity of the $C$. elegans PDFs in a heterologous assay. To this end, we perform and report on pigmentdispersing assays in the shrimp Palaemon pacificus using C. elegans PDFs. From this data, we conclude that the core sequence necessary for binding to a crustacean PDH receptor is preserved in $C$. elegans PDF-1a and b peptides. Furthermore, we compare and discuss the peptide precursor proteins of several PDH and C. elegans PDF peptides, as well as comparing the Daphnia pulex $\mathrm{PDH}$ receptor (identified in silico) with the Drosophila melanogaster and C. elegans PDF receptors.

\section{Materials and methods}

\subsection{Sequence alignments}

Multiple sequence alignments were performed using MUSCLE [6], ClustalW (http://www.ebi.ac.uk/Tools/msa/ clustalw2/) and BoxShade 3.21 (http://www.ch.embnet.org/ software/BOX_form.html). Signal peptides were predicted using SignalP 3.0 (http://www.cbs.dtu.dk/services/SignalP/) and transmembrane helices were predicted using the TMHMM server (http://www.cbs.dtu.dk/services/TMHMM/).

\subsection{Animals}

Shrimps (P. pacificus) were netted in the waters of the harbor of Kalk Bay near Cape Town, South Africa. Animals were maintained in rectangular glass tanks with recirculating sea water as described previously [21]. A few days before use in experiments, shrimps were subjected to living on a white background with a $24 \mathrm{~h}$ light regime for the animals to become light adapted and to display pigment concentration.

\subsection{In vivo pigment dispersion bioassay}

Light-adapted shrimps were collected from the aquarium and kept in a white bucket in the laboratory in aerated sea water. Shrimps were individually inspected for the degree of pigment concentration on the dorsal abdomen with a Nikon dissecting microscope (16× magnification) prior to injection. Staging of chromatophoral red/orange and yellow pigment was done according to Hogben and Slome, 1931 [11]. Three $\mu$ l sea water or peptide dissolved in sea water was injected through the lateral thoracic carapace of the shrimp with a $10 \mu \mathrm{l}$ Hamilton glass syringe. Immediately after injection, each shrimp was placed in a white basin with sea water. Shrimps were monitored using the dissecting microscope at $5 \mathrm{~min}$ intervals over $30 \mathrm{~min}$ to assess chromatophoral stage.

The $C$. elegans PDF peptides and a $C$. elegans peptide of similar length, namely Ce-NLP-42b (SALLQPENNPEWNQLGWAWamide) were custom synthesized by GL Biochem Ltd. (Shanghai), monitored for purity by RP-HPLC and MALDI-TOF MS and finally quantified with the bicinchoninic acid (BCA) protein assay [40] and the NanoDrop-1000 spectrophotometer (Thermo Fisher Scientific). P. clarkii PDH was custom synthesized by Kevin D. Clark (Department of Entomology, University of Georgia, USA) and supplied with a purity of over $95 \%$. Stock solutions were prepared by weight in distilled water and dilute solutions for injection were prepared in sterile sea water.

\section{Results}

\subsection{Sequence analysis of crustacean PDH and C. elegans PDF peptides and precursor proteins}

Currently, 28 crustacean PDH peptides are known through either purification or deduction from cDNA sequences (Table 1). Although most $\mathrm{PDH}$ peptides have been identified by actual purification, several decapod PDH peptide precursors have also been identified by cDNA sequencing: Cancer productus [12,13], Carcinus maenas [16], Callinectes sapidus [17], Litopenaeus vannamei [5,25], Marsupenaeus japonicus [25] and Orconectes limosus [4] (Fig. 1). In addition, PDH precursors of the isopod Armadillidium vulgare [8] and the cladoceran D. pulex [38] are also known. All of these PDH precursor proteins are similarly structured with a signal peptide on the N-terminal side, followed by a PDH precursor related peptide (PPRP) and one C-terminal PDH peptide with a C-terminal amidation site (Gly), flanked by two dibasic amino acid (Arg-Arg or Lys-Arg) cleavage sites (Fig. 1). With 82 and 169 amino acids respectively, $A$. vulgare and $D$. pulex precursor proteins are longer compared to the decapod precursors which contain only 76-80 amino acids; these non-decapod crustacean precursor proteins also deviate considerably in amino acid residue composition, except in the PDH sequence area (Fig. 1). C. elegans produces three PDF precursors: $p d f-1 a$ and $b$ which differ by only two amino acids at positions 125 and 126, encoded by the $p d f-1$ gene, and one encoded by the $p d f-2$ gene [15]. Although the main features (i.e. signal peptide, PDF associated peptide also known as linking peptide, and the C-terminal PDH/PDF peptide) of PDH precursors are conserved (see Fig. 1), C. elegans pdf-1 $a$ and $b$ precursors distinguish themselves by containing two PDF peptides: PDF-1a and b [15, Fig. 1].

Mature PDH peptides are categorized as $\alpha$ - and $\beta$-PDH peptides, the features of which can be seen in Table 1: $\alpha$-PDH peptides are distinguished from $\beta$-PDH peptides by the Gly ${ }^{3}$ and Met $^{4}$ residues, while $\beta$-PDHs display $\mathrm{Glu}^{3}$ and Leu ${ }^{4}$. U. pugilator $\beta$-PDH can be found in at least seven other species making it the most prevalent variant of $\beta$-PDH [36] (Table 1). Amino acid residues are considered identical and therefore conserved when present in at least $50 \%$ of the regarded sequences. Table 1 gives an overview of these conserved residues which are highlighted in black. The N-terminal NSELIN sequence is conserved in all $\beta$-PDH sequences but not in $\alpha$ $\mathrm{PDH}$ and most variability is found in the C-terminal part (Table 1 ), suggesting that this region is less important for activity. The $C$. elegans PDF peptides have very few conserved residues in the $\mathrm{C}$ terminal part, while PDF-1a and b share a conserved N-terminal core sequence (N-ELIN) which is not present in PDF-2 (Table 1).

\subsection{Sequence analysis of $P D H$ and $P D F$ receptors}

Until recently, there was no information available on $\mathrm{PDH}$ receptors in crustaceans. The genome of the branchiopod crustacean $D$. pulex [3] is now predicted to contain at least one PDH receptor (EFX90264). It is predicted to encompass seven membrane spanning regions according to TMHMM Server 2.0 (http://www.cbs.dtu.dk/services/TMHMM/). We have aligned the 


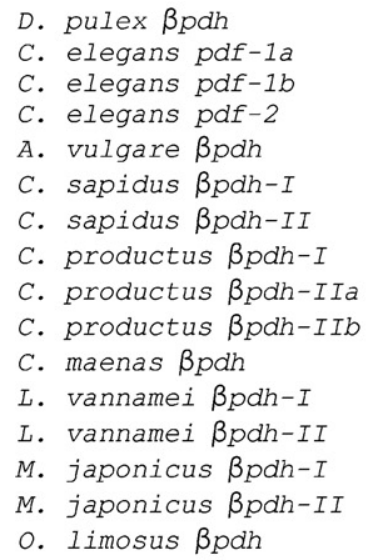

D. pulex $\beta p d h$

C. elegans pdf-1a

C. elegans pdf-1b

C. elegans pdf-2

A. vulgare $\beta p d h$

C. sapidus $\beta p d h-I$

C. sapidus $\beta p d h-I I$

C. productus $\beta p d h-I$

C. productus $\beta p d h-I I a$

C. productus $\beta p d h-I I b$

C. maenas $\beta p d h$

L. vannamei $\beta p d h-I$

L. vannamei $\beta p d h-I I$

M. japonicus $\beta p d h-I$

M. japonicus $\beta p d h-I I$

o. limosus $\beta p d h$
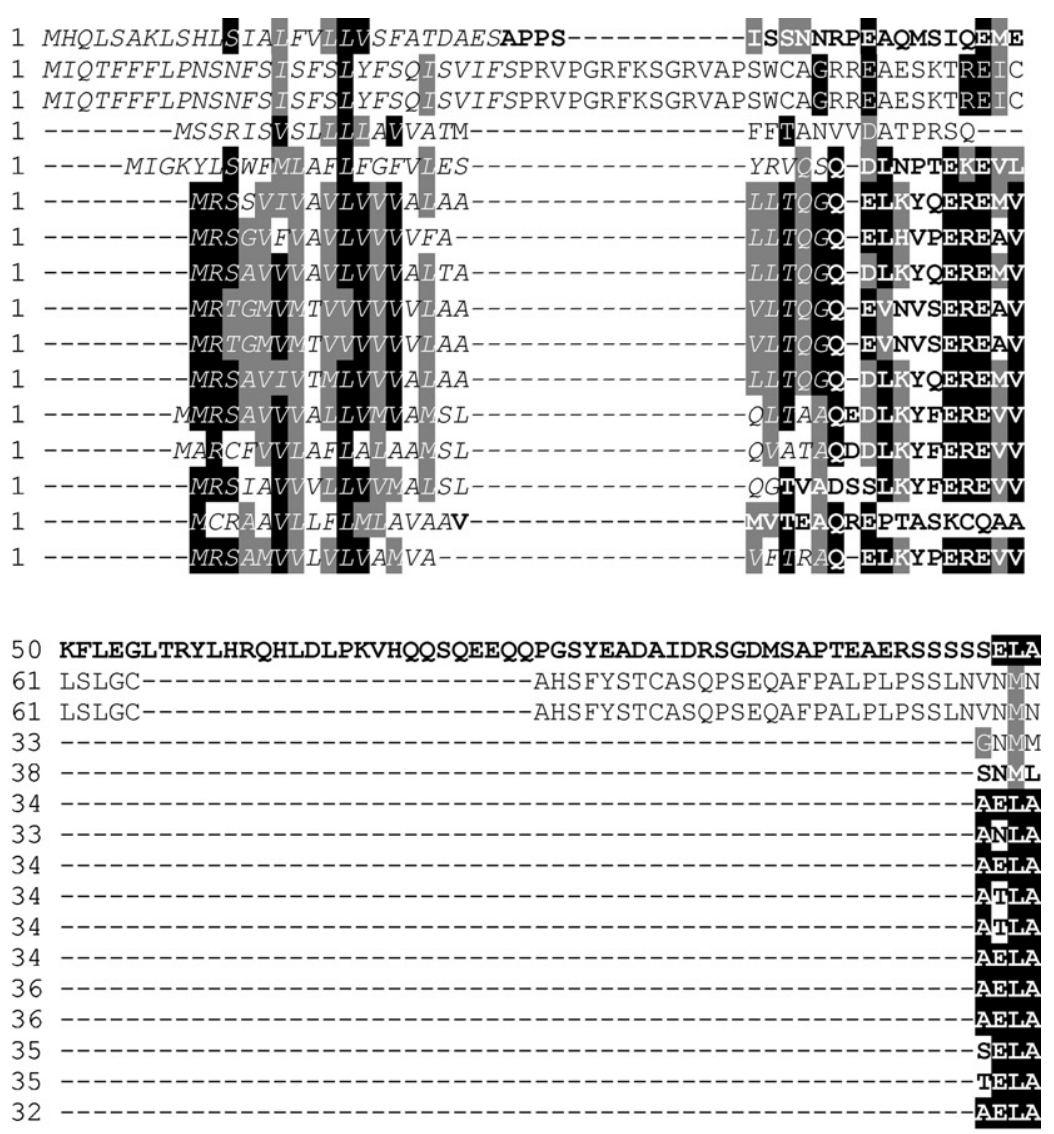

D. pulex $\beta p d h$

C. elegans pdf-1a

C. elegans pdf-1b

C. elegans pdf-2

A. vulgare $\beta p d h$

C. sapidus $\beta p d h-I$

C. sapidus $\beta p d h-I I$

C. productus $\beta p d h-I$

C. productus $\beta p d h-I I a$

C. productus $\beta p d h-I I b$

C. maenas $\beta p d h$

L. vannamei $\beta p d h-I$

L. vannamei $\beta p d h-I I$

M. japonicus $\beta p d h-I$

M. japonicus $\beta$ pdh-II

O. limosus $\beta p d h$

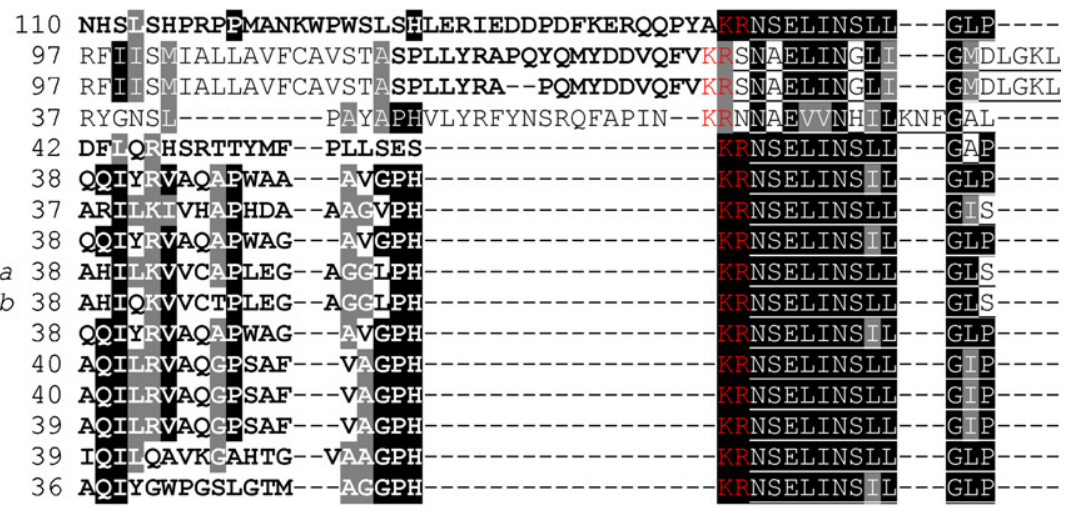

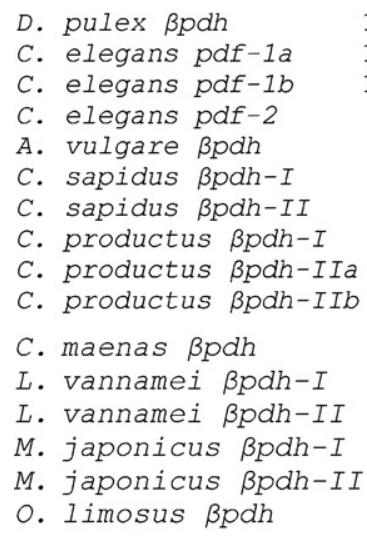

D. pulex $\beta$ pdh

C. elegans pdf-1a

C. elegans pdf-2

A. vulgare $\beta p d h$

C. sapidus $\beta p d h-I$

C. sapidus $\beta$ pdh-I

C. productus $\beta p d h-I$

C. productus $\beta$ pdh-IIa

C. productus $\beta p d h-I I b$

C. maenas $\beta p d h$

L. Vannamei $\beta p d h-I$

M. japonicus $\beta$ pdh-II

O. Iimosus $\beta$ pdh

Fig. 1. Alignment of crustacean PDH- and C. elegans PDF precursor proteins. Crustacean and C. elegans precursors are similarly structured, starting with a signal peptide (predicted by SignalP 3.0 and italicized) followed by a PDH precursor related peptide (PPRP) or linking peptide (both printed bold) and the PDH/PDF peptides at the Cterminal end (for references: see text). Identical amino acids are highlighted in black, conserved amino acids in dark gray. Proteolytic cleavage sites (Lys and/or Arg) are red, amidation sites (Gly) are green and PDH/PDF peptides are underlined (MUSCLE [6] and BoxShade 3.21). (For interpretation of the references to color in this figure legend, the reader is referred to the web version of the article.)

Please cite this article in press as: Meelkop E, et al. A structural and functional comparison of nematode and crustacean PDH-like sequences. Peptides (2012), doi:10.1016/j.peptides.2011.11.008 
Table 1

Sequence alignment of crustacean PDH and C. elegans PDF peptides. Identical amino acids are highlighted in black, conserved amino acids in dark gray (ClustalW2 and BoxShade 3.21).

\begin{tabular}{|c|c|c|c|}
\hline Species & Peptide & Sequence & Reference \\
\hline Orconectes limosus & $\beta$-PDH & TLFGEVamide & [1] \\
\hline Orconectes limosus & $\beta$-PDH C & 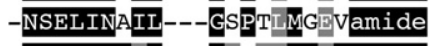 & [1] \\
\hline Cancer borealis & $\beta$-PDH II & MNEAamide & {$[20]$} \\
\hline Cancer productus & $\beta$-PDH II & Aamide & {$[9,12,13]$} \\
\hline Callinectes sapidus & $\beta$-PDH II & amide & [17] \\
\hline Pacifastacus leniusculus & $\beta$-PDH I & -NSELINSIL & [35] \\
\hline Uca pugilator & $\beta$-PDH & -NSELINSII & [36] \\
\hline Neohelice granulata & $\beta-\mathrm{PDH}$ & -NSELINSIL & ACN29625.1 \\
\hline Carcinus maenas & $\beta$-PDH & Aamide & [16] \\
\hline Cancer productus & $\beta$-PDH I & Aamide & {$[9,12,13]$} \\
\hline Cancer magister & $\beta$-PDH & Aamide & {$[18]$} \\
\hline Cancer borealis & $\beta$-PDH I & Aamide & [20] \\
\hline Callinectes sapidus & $\beta$-PDH I & ELINSIL & [17] \\
\hline Oroconetes immunis & $\beta$-PDH & Aamide & [35] \\
\hline Orconectes limosus & $\beta-\mathrm{PDH}$ & Aamide & {$[1,4]$} \\
\hline Procambarus clarkii & $\beta-\mathrm{PDH}$ & Aamide & [22] \\
\hline Pandalus borealis & $\alpha-\mathrm{PDH}$ & de & [7] \\
\hline Pandalus jordani & $\alpha$-PDH II & le & [34] \\
\hline Macrobrachium & $\alpha-\mathrm{PDH}$ & & [31] \\
\hline \multicolumn{4}{|l|}{ rosenbergii } \\
\hline Pandalus jordani & $\alpha$-PDH III & de & [34] \\
\hline Litopenaeus vannamei & $\beta$-PDH B & de & {$[5,26]$} \\
\hline Litopenaeus vannamei & $\beta$-PDH A & amide & {$[5,26]$} \\
\hline Penaeus aztecus & $\beta$-PDH & amide & [30] \\
\hline Marsupenaeus japonicus & $\beta$-PDH I & Lde & {$[25,42]$} \\
\hline Pandalus jordani & $\beta$-PDH I & & [34] \\
\hline Daphnia pulex & $\beta$-PDH & & [14] \\
\hline Marsupenaes japonicus & $\beta$-PDH II & & {$[25,42]$} \\
\hline Armadillidium vulgare & $\beta$-PDH & nide & [12] \\
\hline Caenorhabditis elegans & PDF-2 & vamide & [15] \\
\hline Caenorhabditis elegans & PDF-1a & IG--MDLGKLSAVamide & [15] \\
\hline Caenorhabditis elegans & PDF-1b & SS--MNLNKLSGAamide & [15] \\
\hline
\end{tabular}

putative D. pulex PDF receptor with the receptors of $C$. elegans and D. melanogaster (Fig. 2): our alignment shows a clear conservation of the seven transmembrane (7TM) domains. In addition, several Cys, Trp and Asp residues (characteristic of secretin type $G$ proteincoupled receptors (GPCRs)) [10] are almost perfectly conserved. The first $\mathrm{N}$-terminal extracellular region contains several of these residues which are thought to be important in ligand binding. Also, two of the extracellular regions between TM2 and TM3 and TM4 and TM5, contain cysteine-bridge forming Cys residues (supposedly important in ligand interaction) [27]. Overall, these PDH/PDF receptors share a high degree of similarity even outside the 7TM regions. The D. pulex PDH receptor shows 29.3, 28.9 and $29.4 \%$ sequence identity and $49.5,49.6$ and $49.2 \%$ similarity with the $C$. elegans PDFR-1a, b and c respectively, and $33.2 \%$ identity and $47.4 \%$ similarity with the $D$. melanogaster PDF receptor, suggesting that it is more closely related to the D. melanogaster PDF receptor.

\subsection{In vivo pigment dispersion bioassay}

Like other malacostracan crustaceans, the shrimp $P$. pacificus possesses branched epidermal pigment cells called chromatophores. There are four types of chromatophores according to the color of the pigment granules they contain: erythrophores, xanthophores, leukophores and melanophores, containing respectively red, yellow, white and black or brown granules [see also 21]. In $P$. pacificus, the different chromatophores appear to be stacked on top of each other with blue-black pigment at the base, yellow in the middle and red-orange pigment visible on the surface level of the epithelium; this can be clearly seen in dark-adapted specimens where pigment in the melanophores, xanthophores and erythrophores are dispersed (see for example Fig. 2 in [21]). In the current study, only shrimps that were completely light adapted, i.e. displayed a chromatophoral index of stage 1 , were used in the assays. These specimens had an overall light appearance which manifested microscopically as an epithelium with tiny red dots-each dot representing a chromatophore with concentrated pigment therein (results not shown).

From Table 2 it is clear that the injection of sea water and the handling of shrimps during the microscopic assessments did not have much influence on the pigments movements: the epidermal pigments remained in the concentrated state (index stage 1.2). A similar result was observed in shrimps that were injected with a non-PDH-like C. elegans peptide (NLP-42b), regardless of the dose injected (index stage 1.1; Table 2). The macroscopic appearance of shrimps injected with sea water was also identical to that of NLP-42b injected shrimps, namely light overall with a pattern of red dots, representing the concentrated pigments of the chromatophores (not shown). In contrast, shrimps that were injected with a low dose $(2.5 \mathrm{nmol})$ of $P$. clarkii PDH had a macroscopically darker appearance (not shown): microscopically, two different sets of pigments were in an advanced state of dispersion: the yellow pigment (in xanthophores) were fully dispersed in nearly all of the shrimps (Table 2: index stage 4.5 ), while the red pigments (in erythrophores) were in an intermediate stage of dispersion (Table 2: mean index stage 3.4). Light-adapted P. pacificus that were injected with 3, 6 and $10 \mathrm{nmol}$ of $C$. elegans PDF-1a displayed a similar macroscopic and microscopic appearance to those injected with the crayfish PDH: Table 2 shows that at a low dose, PDF-1a 


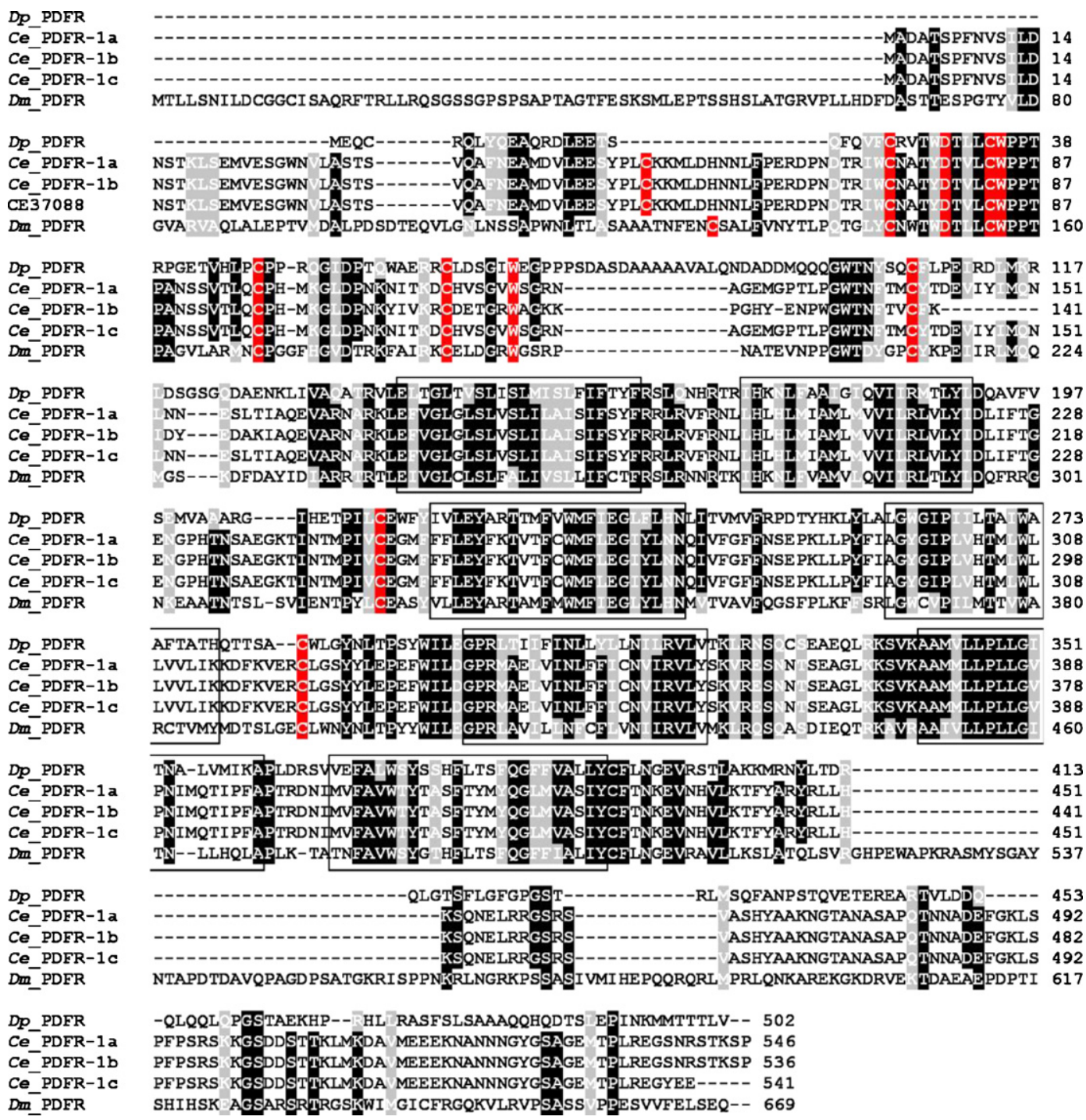

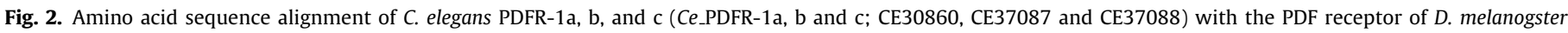

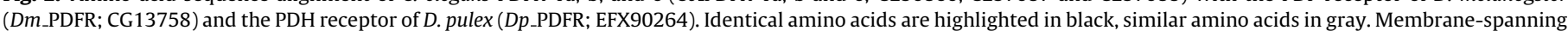

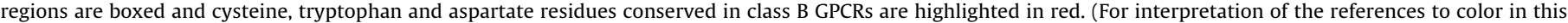
figure legend, the reader is referred to the web version of the article.)

Table 2

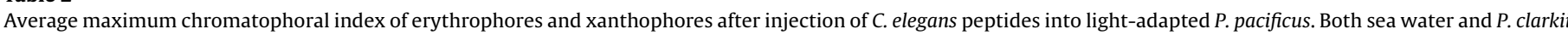

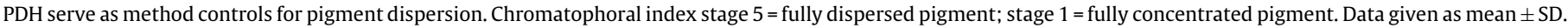
Shrimps were monitored at $5 \mathrm{~min}$ intervals for $30 \mathrm{~min}$.

\begin{tabular}{|c|c|c|c|c|}
\hline Peptide injected & & Dose injected (nmol) & Dispersion index: erythrophores & Dispersion index: xanthophores \\
\hline \multirow[t]{3}{*}{ C. elegans PDF-1a } & SNAELINGLIGMDLGKLSAVamide & 3 & $3.0 \pm 1.2 ; n=7$ & $4.1 \pm 1.2 ; n=7$ \\
\hline & & 6 & $3.4 \pm 0.8 ; n=10$ & Not visible $; n=10$ \\
\hline & & 10 & $3.5 \pm 1.0 ; n=10$ & Not visible ${ }^{\mathrm{a}} ; n=6$ \\
\hline \multirow[t]{3}{*}{ C. elegans PDF-1b } & SNAELINGLLSMNLNKLSGAamide & 3 & $1.1 \pm 0.4 ; n=7$ & $3.1 \pm 1.1 ; n=7$ \\
\hline & & 6 & $1.0 \pm 0.0 ; n=9$ & $2.5 \pm 0.7 ; n=10$ \\
\hline & & 10 & $2.1 \pm 1.1 ; n=5$ & $3.4 \pm 0.4 ; n=5$ \\
\hline \multirow[t]{3}{*}{ C. elegans PDF-2 } & NNAEVVNHILKNFGALDRLGDVamide & 3 & $1.8 \pm 1.2 ; n=9$ & $2.5 \pm 1.3 ; n=9$ \\
\hline & & 6 & $1.1 \pm 0.2 ; n=10$ & $2.4 \pm 1.3 ; n=10^{\mathrm{b}}$ \\
\hline & & 10 & $1.2 \pm 0.4 ; n=5$ & $1.5 \pm 0.9 ; n=5$ \\
\hline P. clarkii PDH & NSELINSILGLPKVMNEAamide & 2.5 & $3.4 \pm 1.0 ; n=9$ & $4.5 \pm 0.8 ; n=9$ \\
\hline \multirow[t]{2}{*}{ C. elegans NLP-42b } & SALLQPENNPEWNQLGWAWamide & 10 & $1.0 \pm 0.0 ; n=5$ & $1.0 \pm 0.0 ; n=5$ \\
\hline & & 15 & $1.1 \pm 0.4 ; n=5$ & $1.0 \pm 0.0 ; n=5$ \\
\hline Sea water & - & - & $1.2 \pm 0.4 ; n=9$ & $1.0 \pm 0.0 ; n=9$ \\
\hline
\end{tabular}

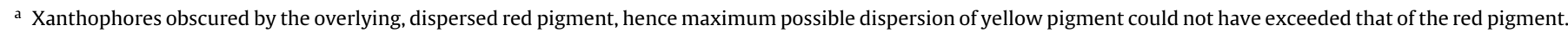

b Only four out of 10 animals had yellow pigments dispersed.

Please cite this article in press as: Meelkop E, et al. A structural and functional comparison of nematode and crustacean PDH-like sequences. Peptides (2012), doi:10.1016/j.peptides.2011.11.008 
dispersed both red and yellow pigments, whereas with higher doses, PDF-1a had marginally stronger dispersion effects on red pigments. Since red pigment is the most superficial, it is possible that the underlying yellow pigment is also dispersed, but is obscured; be that as it may, a dose-response effect of PDF-1a is evident on erythrophores (Table 2). Interestingly, $10 \mathrm{nmol} \mathrm{PDF-1a}$ elicited a strong red pigment-dispersing effect (index stage ranging from 3.5 to 4.5 ) in $67 \%$ of the shrimps injected, while in the remaining $37 \%$ only a weaker response was noted (index stage range of 2-2.5). A notable different response, with regards to dispersion of red pigment, was observed after injection of PDF-1b and PDF-2 (Table 2): these peptides did not disperse pigment in erythrophores and red pigment remained relatively concentrated (mean index stage ranging from 1 to 2.1 ) even $30 \mathrm{~min}$ after injection. On the other hand, $C$. elegans PDF-1b elicited low to intermediate dispersion responses (mean index between stages 2.5 and 3.4) in xanthophores (Table 2). In these instances, the red pigment was visible as a small dot (concentrated), while the chromatophoral branches surrounding this, were filled with yellow pigment (not shown). A dose-response is evident, with $10 \mathrm{nmol}$ PDF- $1 \mathrm{~b}$ having the strongest effect (Table 2). PDF-2, however, did not have a convincing and consistent pigment-dispersing effect in the shrimp, even at the highest dose tested $(10 \mathrm{nmol})$. The high standard deviation recorded with dispersion of yellow pigment by doses of 3 and $6 \mathrm{nmol}$ PDF-2 (see Table 2) resulted from such inconsistencies: $44 \%$ of the injected shrimps reacted with an intermediate to strong dispersion (mean index ranging from stages 3 to 4 ), whereas the remaining 66\% hardly reacted (mean index ranging from stages 1 to 2 ).

\section{Discussion}

We examined whether the C. elegans PDF peptides display functional cross-activity in a crustacean and whether they are able to elicit pigment dispersing responses. Injection of $C$ elegans PDF-1a into light adapted $P$. pacificus resulted in clear pigment dispersing responses of both erythrophores and xanthophores. PDF-1b and PDF-2 were inactive for erythrophore dispersion but were able to induce a response in xanthophores. In the case of PDF$1 \mathrm{~b}$, this effect was dose-dependent, whereas this does not seem to be the case with PDF-2. Hence, we can state unequivocally that the C. elegans PDF peptides (PDF-1a and PDF-1b) are indeed functionally conserved. The inconsistent pigment-dispersing effect of PDF-2 either points to improper binding to the crustacean receptor and/or steric hindrance that may affect the biological response. It is known that the structural requirements for pigment dispersing potency can vary according to the type of target cell, both within and between species [30]. Although no reports thus far exist on PDH potency comparison in P. pacificus, pigment dispersion seems to be more complicated than originally considered. When the shrimps are left in the dark for a few days, they become dark-adapted with a complex display of all three pigments (blue, yellow and red) in a dispersed state (visually layered; see [21]). None of the PDH/F peptides used in the current study could mimic this natural dispersion: blue pigment was never obviously dispersed, and the red pigment was either not affected, or was so dispersed that it obscured the yellow pigment. These observations hint that different factors may affect different chromatophores, or that the PDH receptor on different chromatophores may be unique for each type of chromatophore, or have different peptide binding sites. Until we have more information about the number and structure of PDHs and their receptors in $P$. pacificus, we cannot solve the anomaly of why certain peptides used in this study only affected xanthophores, or both erythrophores and xanthophores.
A considerable number of studies used the melanophores of the fiddler crab U. pugilator [29,32]. The first sequenced non-crustacean PDH-like substance to be tested in $U$. pugilator was PDF from R. microptera: NSEIINSLLGLPKLLNDAamide which differs from $U$. pugilator PDH at four positions: $\mathrm{Ile}^{4}$ Leu $^{8}$, Leu ${ }^{14}$ and Leu ${ }^{15}$ causing R. microptera PDF to be $50 \%$ less potent compared to U. pugilator $\mathrm{PDH}$ [32]. U. pugilator was used to determine the relative pigment dispersing potency of several other PDH-like peptides of crustaceans and insects as well as structural intermediates of $\alpha$ - and $\beta-P D H$ [31]. While substitutions in the C-terminal part (positions 11, 13, 16 and 17) of $P$. borealis $\alpha$-PDH (NSGMINSILGIPRVMTEAamide) did not significantly increase the relatively low pigment dispersing potency of the peptide, substitutions at positions 3 and 4 did increase it up to four times when changing both $\mathrm{Gly}^{3}$ and $\mathrm{Met}^{4}$ to $\mathrm{Glu}^{3}$ and Leu ${ }^{4}$, respectively [31]. The N-terminal NSELIN sequence is conserved in all $\beta$-PDH sequences, including $P$. clarkii $\mathrm{PDH}$ (but replaced by NSGMIN in $\alpha$-PDH), pointing to the importance of this fraction in maintaining biological activity in certain decapod systems.

C. elegans PDF peptides differ from crustacean PDHs which are all octadecapeptides: PDF-1a and b both comprise 20 amino acids while PDF-2 is longer ( 22 residues). The $\mathrm{N}$-terminal NSELIN sequence found in crustacean $\beta-\mathrm{PDH}$ is not completely conserved in $C$. elegans since $\mathrm{Ser}^{2}$ has changed to $\mathrm{Ala}^{3}$. The potent $\mathrm{Glu}^{4}$ and Leu $^{5}$ residues ( $\mathrm{Glu}^{3}$ and $\mathrm{Leu}^{4}$ in crustaceans) however, are maintained in PDF-1a and b. The fact that PDF-2 was not as successful in eliciting pigment dispersion in light-adapted $P$. pacificus as the PDF1 peptides could be explained by substitutions of $\mathrm{Glu}^{4}$ and $\mathrm{Leu}^{5}$ by $\mathrm{Val}^{4}$ and $\mathrm{Val}^{5}$. As discussed above, the fact that PDF-1b fails to elicit a response in erythrophores cannot yet be explained since PDF-1a and $b$ differ from each other at 6 positions outside the $\mathrm{N}$-terminal core sequence (N-ELIN) which seems to be important for activation of the decapod PDH receptor.

When comparing the $C$. elegans PDF precursors to crustacean PDH precursors, the overall structure of the precursor protein has been conserved although signal peptide and precursor associated peptide sequences are entirely different. While the signal peptides consist of short sequences and mediate the correct translocation of precursor proteins across the endoplasmic reticulum membrane after translation, the function of the PPAPs and linking peptides remains unknown. The great variation observed among signal peptides in general, implies that many different sequences can direct membrane transport. Signal peptides appear to evolve faster when compared to the corresponding mature peptides and this evolution is not neutral, since they do undergo functional selective pressure [41]. In addition, $C$. elegans $p d f-1 a$ and $b$ precursors, both give rise to two mature PDF peptides: PDF-1a and PDF-1b, which is never the case in crustaceans. Instead, several crustaceans including M. japonicus [25,42], C. productus [9,12,13], O. limosus [1] and $L$. vannamei $[5,26]$ express different $\mathrm{PDH}$ peptides, originating from different precursor proteins. The presence of different PDH peptides in one animal suggests that they each function in different locations and/or in different processes. This hypothesis is supported by the work on $C$. productus [13] and C. sapidus [17] which shows different expression patterns (the neurosecretory sinus gland or other, non-secretory, parts of the sinus gland) for the different PDH peptides, suggesting that they either act as neurohormones, as local neurotransmitters and/or modulators. The fact that both C. elegans precursors only differ in two amino acids from each other, makes it difficult to distinguish them on both transcriptional and protein level. The same is true for the mature PDF-1a and b peptides, which contain only two non-identical or non-similar amino acids. Thus far, it is not known whether PDF-1a and b peptides fulfill different roles.

Since a few years, it is known that D. melanogaster PDF binds to a class B, or secretin type GPCR, which uses G $\alpha$ s and cAMP as 
second messengers [24]. Until very recently, nothing was known about crustacean PDH receptors. The publication of the first crustacean genome sequence, being that of $D$. pulex, enables us to now compare, for the first time, a crustacean PDH receptor to the $D$. melanogaster and $C$. elegans PDF receptors. The putative $D$. pulex $\mathrm{PDH}$ receptor is predicted to contain seven transmembrane spanning regions and contains nearly all (one Cys residue in the $\mathrm{N}$-terminal extracellular domain is missing) conserved residues typical for secretin type receptors [10]. Based on amino acid sequence identity, the $D$. pulex $\mathrm{PDH}$ receptor is more similar to the D. melanogaster PDF receptor than either of the three $C$. elegans receptors.

PDH was one of the first neuropeptides to be characterized in crustaceans [7] and pigment dispersing factors (PDFs) could thereafter be identified in insects as well [32], where they function as important output signals of the endogenous circadian clock [28]. Also in crustaceans, $\mathrm{PDH}$ is proposed to be more than just a pigment dispersing peptide as recently it could be linked to the circadian clock of P. clarkii, C. destructor [39] and D. pulex [38], the latter which is transparent and probably lacks true chromatophores. With the discovery of PDF in the nematode $C$. elegans, the possibility arose to investigate PDF functions in another ecdysozoan representative $[14,15]$ and its putative role in locomotion, reproduction and circadian rhythms is currently under investigation. Although C. elegans PDF peptides differ in length compared to their arthropod family members, the core sequence responsible for PDH receptor activation still seems to be present.

\section{Acknowledgements}

We like to thank L. Vandenbosch for the technical assistance in peptide purification and quantification. Shrimps were supplied by Ms Andrea Plos (Zoology Department, University of Cape Town). EM benefits from a PhD grant of the Agency for Innovation by Science and Technology (IWT); TJ, LT and MV benefit grants from the Research Foundation-Flanders (FWO). Part of the research was financially sponsored by a grant from the National Research Foundation (GUN No. 61107) and a block grant from the University of Cape Town Research Council awarded to HGM.

\section{References}

[1] Bulau P, Meisen I, Schmitz T, Keller R, Peter-Katalinic J. Identification of neuropeptides from the sinus gland of the crayfish Orconectes limosus using nanoscale on-line liquid chromatography tandem mass spectrometry. Mol Cell Proteomics 2004;3:558-64.

[2] Christie AE, Stemmler EA, Dickinson PS. Crustacean neuropeptides. Cell Mol Life Sci 2010;67:4135-69.

[3] Colbourne JK, Pfrender ME, Gilbert D, Thomas WK, Tucker A, Oakley TH, et al. The ecoresponsive genome of Daphnia pulex. Science 2011;331:555-61.

[4] DeKleijn DPV, Linck B, Klein JM, Weidemann WM, Keller R, Van Herp F. Structure and localization of messenger-RNA encoding a pigment dispersing hormone $(\mathrm{PDH})$ in the eyestalk of the crayfish Orconectes limosus. FEBS Lett 1993:321:251-5.

[5] Desmoucelles-Carette C, Sellos D, Van Wormhoudt WA. Molecular cloning of the precursors of pigment dispersing hormone in crustaceans. Biochem Biophys Res Commun 1996;221:739-43.

[6] Edgar RC. MUSCLE: multiple sequence alignment with high accuracy and high throughput. Nucleic Acids Res 2004;32:1792-7.

[7] Fernlund P. Structure of a light-adapting hormone from shrimp, Pandalus borealis. Biochim Biophys Acta 1976;439:17-25.

[8] Fouda MM, Hiragaki S, Tufail M, Shao QM, Takeda M. Precursor structure, distribution and possible functions of pigment-dispersing hormone (PDH) in the terrestrial isopod Armadillidium vulgare (Latreille). J Insect Physiol 2010;56:1728-37.

[9] Fu Q Kutz KK, Schmidt JJ, Hsu YW, Messinger DI, Cain SD, et al. Hormone complement of the Cancer productus sinus gland and pericardial organ: an anatomical and mass spectrometric investigation. J Comp Neurol 2005;493:607-26.

[10] Harmar AJ. Family-B G-protein-coupled receptors. Genome Biol 2001;2:3013 [Reviews].
[11] Hogben L, Slome D. The pigmentary effector system. VI. The dual character of endocrine co-ordination in amphibian colour change. Proc Roy Soc Lond Ser B: Containing Pap Biol Charact 1931;108:10-53.

[12] Hsu YW, Stemmler EA, Messinger DI, Dickinson PS, Christie AE, De La Iglesia HO. Erratum: Cloning and differential expression of two beta-pigment-dispersing hormone (beta-PDH) isoforms in the crab Cancer productus: evidence for authentic beta-PDH as a local neurotransmitter and beta-PDH II as a humoral factor. J Comp Neurol 2010;518:4674.

[13] Hsu YWA, Stemmler EA, Messinger DI, Dickinson PS, Christie AE, De la Iglesia HO. Cloning and differential expression of two beta-pigment-dispersing hormone (beta-PDH) isoforms in the crab Cancer productus: evidence for authentic beta-PDH as a local neurotransmitter and beta-PDH II as a humoral factor. J Comp Neurol 2008;508:197-211.

[14] Janssen T, Husson SJ, Lindemans M, Mertens I, Rademakers S, Ver Donck DK, et al. Functional characterization of three G protein-coupled receptors for pigment dispersing factors in Caenorhabditis elegans. J Biol Chem 2008;283:15241-9.

[15] Janssen T, Husson SJ, Meelkop E, Temmerman L, Lindemans M, Verstraelen $\mathrm{K}$, et al. Discovery and characterization of a conserved pigment dispersing factor-like neuropeptide pathway in Caenorhabditis elegans. J Neurochem 2009;111:228-41.

[16] Klein JM, De Kleijn DP, Keller R, Weidemann WM. Molecular cloning of crustacean pigment dispersing hormone precursor. Biochem Biophys Res Commun 1992;189:1509-14.

[17] Klein JM, Mohrherr CJ, Sleutels F, Riehm JP, Rao KR. Molecular cloning of two pigment-dispersing hormone $(\mathrm{PDH})$ precursors in the blue crab Callinectes sapidus reveals a novel member of the $\mathrm{PDH}$ neuropeptide family. Biochem Biophys Res Commun 1994;205:410-6.

[18] Kleinholz LH, Rao KR, Riehm JP, Tarr GE, Johnson L, Norton S. Isolation and sequence-analysis of a pigment-dispersing hormone from eyestalks of the Crab, Cancer magister. Biol Bull 1986;170:135-43.

[19] Koller G. Uber chromatophorensystem, Farbensinn und Farbwechsel bei Crangon vulgaris. Z Vergleich Physiol 1927;5:191-246.

[20] Ma M, Wang J, Chen R, Li L. Expanding the Crustacean neuropeptidome using a multifaceted mass spectrometric approach. J Proteome Res 2009;8:2426-37.

[21] Marco HG, Gäde G. Biological activity of the predicted red pigmentconcentrating hormone of Daphnia pulex in a crustacean and an insect. Gen Comp Endocrinol 2010;166:104-10.

[22] McCallum ML, Rao KR, Riehm JP, Mohrherr CJ, Morgan WT. Primary structure and relative potency of an analog of beta-PDH (pigment-dispersing hormone) from the crayfish Procambarus clarkii. Pigment Cell Res 1991;4:201-8.

[23] Meelkop E, Temmerman L, Schoofs L, Janssen T. Signalling through pigment dispersing hormone-like peptides in invertebrates. Prog Neurobiol 2011;93:125-47 [Epub October 30, 2010].

[24] Mertens I, Vandingenen A, Johnson EC, Shafer OT, Li W, Trigg JS, et al. PDF receptor signaling in Drosophila contributes to both circadian and geotactic behaviors. Neuron 2005;48:213-9.

[25] Ohira T, Nagasawa H, Aida K. Molecular cloning of cDNAs encoding two pigment-dispersing hormones and two corresponding genes from the kuruma prawn (Penaeus japonicus). Mar Biotechnol 2002;4:463-70.

[26] Ohira T, Tsutsui N, Kawazoe I, Wilder MN. Isolation and characterization of two pigment-dispersing hormones from the whiteleg shrimp, Litopenaeus vannamei. Zoolog Sci 2006;23:601-6.

[27] Palczewski K, Kumasaka T, Hori T, Behnke CA, Motoshima H, Fox BA, et al. Crystal structure of rhodopsin: a $\mathrm{G}$ protein-coupled receptor. Science 2000;289:739-45

[28] Park JH, Hall JC. Isolation and chronobiological analysis of a neuropeptide pigment-dispersing factor gene in Drosophila melanogaster. J Biol Rhythms 1998;13:219-28.

[29] Petri B, Stengl M. Pigment-dispersing hormone shifts the phase of the circadian pacemaker of the cockroach Leucophaea maderae. J Neurosci 1997;17:4087-93.

[30] Phillips JM, Rao KR, Riehm JP, Morgan WT. Isolation and characterization of a pigment-dispersing hormone from the shrimp, Penaeus aztecus. Soc Neurosci Abstr 1988;14:534.

[31] Rao KR. Crustacean pigmentary-effector hormones: chemistry and functions of RPCH, PDH, and related peptides. Am Zool 2001;41: 364-79.

[32] Rao KR, Mohrherr CJ, Riehm JP. Characterization of a pigment-dispersing factor from the lubber grasshopper, Romalea microptera. Am Zool 1986;26:A55.

[33] Rao KR, Mohrherr CJ, Riehm JP, Zahnow CA, Norton S, Johnson L, et al. Primary structure of an analog of crustacean pigment-dispersing hormone from the lubber grasshopper Romalea microptera. J Biol Chem 1987;262:2672-5.

[34] Rao KR, Riehm JP. The pigment-dispersing hormone family: chemistry, structure-activity relations, and distribution. Biol Bull 1989;177:225-9.

[35] Rao KR, Riehm JP. Pigment-dispersing hormones. Ann N Y Acad Sci 1993;680:78-88

[36] Rao KR, Riehm JP, Zahnow CA, Kleinholz LH, Tarr GE, Johnson L, et al. Characterization of a pigment-dispersing hormone in eyestalks of the fiddler crab Uca pugilator. Proc Natl Acad Sci USA 1985;82:5319-22.

[37] Renn SC, Park JH, Rosbash M, Hall JC, Taghert PH. A pdf neuropeptide gene mutation and ablation of PDF neurons each cause severe abnormalities of behavioral circadian rhythms in Drosophila. Cell 1999;99:791-802.

[38] Strauss J, Zhang Q, Verleyen P, Huybrechts J, Pauels K, Dircksen H. Multiple identified peptidergic interneurons express a novel pigment-dispersing hormone in the Daphnia brain and visual ganglia, some showing evidence for clock-neuron functions. Comp Biochem Physiol A-Mol Integr Physiol 2009;153A:S156-7. 
[39] Sullivan JM, Genco MC, Marlow ED, Benton JL, Beltz BS, Sandeman DC. Brain photoreceptor pathways contributing to circadian rhythmicity in crayfish. Chronobiol Int 2009;26:1136-68.

[40] Wiechelman KJ, Braun RD, Fitzpatrick JD. Investigation of the bicinchoninic acid protein assay: identification of the groups responsible for color formation. Anal Biochem 1988;175:231-7.
[41] Williams EJ, Pal C, Hurst LD. The molecular evolution of signal peptides. Gene 2000;253:313-22.

[42] Yang WJ, Aida K, Nagasawa H. Characterization of chromatophorotropic neuropeptides from the kuruma prawn Penaeus japonicus. Gen Comp Endocrinol $1999 ; 114: 415-24$ 